\title{
Programmable starving-photodynamic synergistic cancer therapy
}

\author{
Leli Zeng ${ }^{1,2}$, Kai Huang ${ }^{1}$, Yilin Wan ${ }^{1}$, Jing Zhang ${ }^{1}$, Xikuang Yao ${ }^{1}$, Chao Jiang ${ }^{1}$, Jing Lin ${ }^{1}$ and \\ Peng Huang ${ }^{1 *}$
}

\begin{abstract}
Synergistic therapy combines multiple therapeutic approaches in one shot, thus could significantly amplify the therapeutic effects. However, how to design the desirable combination to maximize the synergistic effect is still a big challenge in cancer management. Herein, a nanoagent composed of glucose oxidase (GOx) and upconversion nanoparticles (UCNPs) were constructed for programmable starving-photodynamic synergistic cancer therapy through cascade glucose oxidation and hydrogen peroxide photolysis. In this nanoagent, GOx modulated the tumor glucose metabolism and consumed the $\beta$-D-glucose to produce $\mathrm{H}_{2} \mathrm{O}_{2}$. The glucose depletion induced "starvation" in cancer cells and caused cell death. Afterwards, the generated $\mathrm{H}_{2} \mathrm{O}_{2}$ was photolyzed by the invisible ultraviolet emission of UCNPs under near-infrared light excitation at $980 \mathrm{~nm}$. The toxic hydroxyl radicals produced by photolysis further induced cancer cell death. Both in vitro and in vivo experiments confirmed that this starving-photodynamic synergistic therapy significantly outran any single therapy. This study paves an avenue to design programmable starving-photodynamic synergistic therapy for cancer management.
\end{abstract}

Keywords: upconversion nanoparticles, starvation therapy, photodynamic therapy, synergistic cancer therapy

\section{INTRODUCTION}

Synergistic therapy takes advantages of multiple therapeutic approaches at the same time, and is recognized as a revolutionary strategy for cancer therapy [1-5]. However, to achieve " $1+1>2$ " efficiency, researchers have to design the desirable combinations that maximize the cooperative effect of both therapeutic approaches [6] Recently, multifunctional nanoparticles that integrate multiple therapeutic modalities have experienced rapid developments in the recent decade. Obviously, nanomaterials exhibit several prominent advantages in drug delivery and tumor targeting therapy on account of enhanced permeability and retention (EPR) effect and versatile modified properties. Rational design of nanomaterials by combining multiple therapy modalities holds super additive therapeutic effects in cancer treatment [7-10].

As an alternative to the traditional chemotherapeutics, the glucose oxidase (GOx)-based nanomedicines have aroused great research interest in cancer synergistic therapy [11-14]. In such therapeutic systems, GOx usually serves as the driving force thanks to its special biological property. GOx can catalyze the oxidation of $D$ glucose by $\mathrm{O}_{2}$ into the corresponding gluconic acid and $\mathrm{H}_{2} \mathrm{O}_{2}$ [15]. This oxidation process will then lead to the exhaustion of glucose and oxygen, both of which are crucial nutrients for cells, thus greatly inhibiting the energy metabolic mode of cancer cells and causing cell death. Such therapy modality of blocking the crucial nutrients is known as the tumor starving-therapy $[16,17]$. In addition, the generated $\mathrm{H}_{2} \mathrm{O}_{2}$ can further induce reactive oxygen species (ROS)-dependent cell death. Gluconic acid, another product of the oxidation process, can increase the acidity in the tumor microenvironment. Due to the versatile and unique properties, GOx has attracted tremendous interest in cancer synergistic therapy. For instance, we developed GOx- and $L$-arginine-modified hollow mesoporous organosilica nanoparticles ( $L$-ArgHMON-GOx) for GOx-mediated starvation therapy and nitrogen oxide (NO) gas therapy [18]. In this system, glucose was exhausted for starving-like cancer therapy,

\footnotetext{
${ }^{1}$ Marshall Laboratory of Biomedical Engineering, International Cancer Center, Laboratory of Evolutionary Theranostics (LET), School of Biomedical Engineering, Shenzhen University Health Science Center, Shenzhen 518060, China

${ }^{2}$ Research Centre, The Seventh Affiliated Hospital, Sun Yat-sen University, Shenzhen 518107, China

*Corresponding author (email: peng.huang@szu.edu.cn)
} 
while the generated gluconic acid and $\mathrm{H}_{2} \mathrm{O}_{2}$ in the process of glucose oxidation further oxidized $L$-Arg into NO for gas therapy. In addition, the GOx-modified nanomaterials have been reported for starvation/metal-ion therapy [19], starvation/chemodynamic therapy [20], and starvation/chemotherapy [21,22]. However, these synergistic therapeutic outcomes are still limited due to the uncontrollable interactions between the multiple therapeutic modalities. Therefore, it remains a challenge to design a rational GOx-modified nanomaterial system for maximizing the efficiency of chain reactions.

To increase the flexibility and accuracy of synergistic cancer treatment, researchers usually integrate photodynamic therapy (PDT) with GOx-mediated therapy [23]. In PDT, ROS are generated by the photosensitizers (PSs) under laser irradiation for cancer treatment, thus being recognized as a minimal or noninvasive approach. For example, Chang et al. $[24,25]$ developed a GOx-enhanced PDT system using light irradiation at 660 and $460 \mathrm{~nm}$. Their design showed spatiotemporal controlled cancer treatment and amplified synergistic therapeutic effect. However, short-wavelength light can cause damage in normal tissues and has limited tissue-penetration depth [26-28]. Therefore, the development of long-wavelength light-responsive nanomaterials is quite demanding for GOx-involved PDT.

To address the above issues, researchers developed near-infrared (NIR) responsive materials over the last two decades, thus enabling NIR light with deep tissue penetrating and minimal photo damaging characteristics to activate biomolecules [29-33]. As a type of popular NIR materials, upconversion nanoparticles (UCNPs) absorb $980 \mathrm{~nm}$ light and emit invisible/ultraviolet light, which serves as the in situ light source for light-responsive materials in deep tissue. Here, we synthesized GOx conjugated silica-coated UCNPs (UCNPs@SiO $\mathrm{H}_{2} @ \mathrm{GOx}$ ) (Scheme 1a). The UCNPs can absorb NIR light at $980 \mathrm{~nm}$ and converted the low-energy photon to high-energy invisible ultraviolet photon that could trigger $\mathrm{H}_{2} \mathrm{O}_{2}$ photolysis to produce hydroxyl radical $(\cdot \mathrm{OH})[24,34,35]$. After the accumulation of UCNPs@SiO $\mathrm{S}_{2} @ \mathrm{GOx}$ in tumor tissues, intratumoral glucose was oxidized into gluconic acid and produced $\mathrm{H}_{2} \mathrm{O}_{2}$ with the catalysis of GOx. Afterwards, the generated $\mathrm{H}_{2} \mathrm{O}_{2}$ could be converted into . OH via the photolysis. The highly toxic $\cdot \mathrm{OH}$ could effectively increase the toxicity of the nanoagent to tumor cells (Scheme 1b). Consequently, the programmatic and spatiotemporally controlled synergistic therapy manners showed amplified synergistic effects of cancer starvation therapy and PDT with reduced side effects.

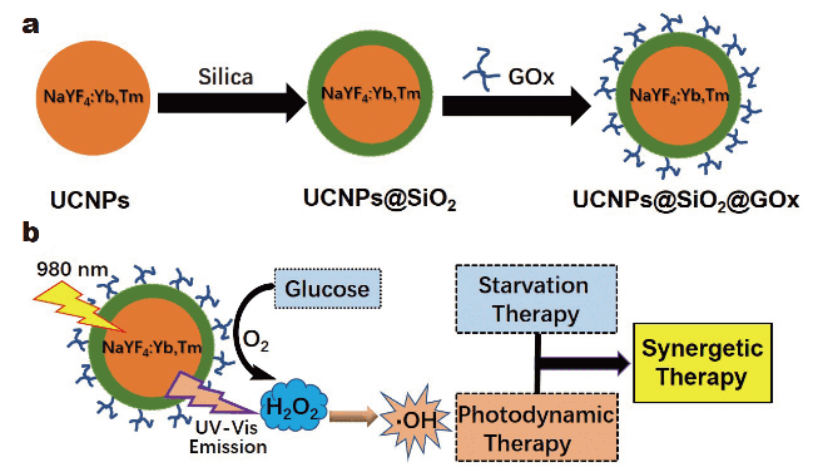

Scheme 1 (a) Synthesis of UCNPs@SiO $\mathrm{S}_{2} @ G O x$; (b) schematic illustration of UCNPs@SiO $@$ @Ox for programmable starving-photodynamic synergistic cancer therapy.

\section{EXPERIMENTAL SECTION}

\section{Synthesis of UCNPs}

The $\mathrm{NaYF}_{4}: 20 \% \mathrm{Yb}, 0.5 \% \mathrm{Tm}$ core UCNPs were prepared by a two-step thermolysis method. In the first step, $\mathrm{CF}_{3} \mathrm{COONa}(0.50 \mathrm{mmol}), \mathrm{Y}\left(\mathrm{CF}_{3} \mathrm{COO}\right)_{3}(0.3975 \mathrm{mmol})$, $\mathrm{Yb}\left(\mathrm{CF}_{3} \mathrm{COO}\right)_{3} \quad(0.10 \mathrm{mmol})$ and $\mathrm{Tm}\left(\mathrm{CF}_{3} \mathrm{COO}\right)_{3}$ $(0.0025 \mathrm{mmol})$ precursors were mixed with oleic acid $(5 \mathrm{mmol})$, oleyamine $(5 \mathrm{mmol})$, and 1 -octadecene $(10 \mathrm{mmol})$ in a two-neck round bottom flask. The mixture was heated to $110^{\circ} \mathrm{C}$ to form a transparent solution followed by $10 \mathrm{~min}$ of degassing. Then the mixture was heated to $300^{\circ} \mathrm{C}$ at a rate of $15^{\circ} \mathrm{C} \mathrm{m^{-1 }}$ under dry argon flow, and maintained at $300^{\circ} \mathrm{C}$ for $30 \mathrm{~min}$ to form the $\alpha$ $\mathrm{NaYF}_{4}: 20 \% \mathrm{Yb}, 0.5 \% \mathrm{Tm}$ intermediate UCNPs. After the mixture was cooled to room temperature, the $a$ $\mathrm{NaYF}_{4}: 20 \% \mathrm{Yb}, 0.5 \% \mathrm{Tm}$ intermediate UCNPs were collected by centrifugal washing with excessive ethanol (7500 $\times \mathrm{g}, 30 \mathrm{~min})$. In the second step, the $\alpha-\mathrm{NaYF}_{4}: 20 \% \mathrm{Yb}, 0.5 \%$ Tm intermediate UCNPs were redispersed into oleic acid $(10 \mathrm{mmol})$ and 1 -octadecene $(10 \mathrm{mmol})$ together with $\mathrm{CF}_{3} \mathrm{COONa}(0.5 \mathrm{mmol})$ in a new two-neck round bottom flask. After degassing at $110^{\circ} \mathrm{C}$ for $10 \mathrm{~min}$, this flask was heated to $325^{\circ} \mathrm{C}$ at a rate of $15^{\circ} \mathrm{C} \mathrm{min}{ }^{-1}$ under dry argon flow, and maintained at $325^{\circ} \mathrm{C}$ for $30 \mathrm{~min}$ to complete the phase transfer from $\alpha$ to $\beta$. After the mixture was cooled to room temperature, the $\beta-\mathrm{NaYF}_{4}: 20 \% \mathrm{Yb}, 0.5 \% \mathrm{Tm}$ UCNPs were collected by precipitation with an equal volume of ethanol and centrifugation afterwards $(7500 \times \mathrm{g}, 30 \mathrm{~min})$. The UCNPs were stored in hexane $(10 \mathrm{~mL})$. The as-synthesized core UCNPs served as cores for the epitaxial growth of core-shell UCNPs. Typically, a hexane stock solution of core UCNPs was transferred into a two-neck round bottom flask, and the hexane was se- 
quentially evaporated by heating. $\mathrm{CF}_{3} \mathrm{COONa}$ $(0.50 \mathrm{mmol})$ and $\mathrm{Y}\left(\mathrm{CF}_{3} \mathrm{COO}\right)_{3}(0.50 \mathrm{mmol})$ were introduced as UCNP shell precursors with oleic acid $(10 \mathrm{mmol})$ and 1 -octadecene $(10 \mathrm{mmol})$. After $10 \mathrm{~min}$ of degassing at $110^{\circ} \mathrm{C}$, the flask was heated to $325^{\circ} \mathrm{C}$ at a rate of $15^{\circ} \mathrm{C} \mathrm{min}{ }^{-1}$ under dry argon flow, and maintained at $325^{\circ} \mathrm{C}$ for $30 \mathrm{~min}$ to complete the shell crystal growth. After the mixture was cooled to room temperature, the $\mathrm{NaYF}_{4}: 20 \% \mathrm{Yb}, 0.5 \% \mathrm{Tm} @ \mathrm{NaYF}_{4}$ core-shell UCNPs were collected by precipitated with an equal volume of ethanol and centrifugation afterwards $(7500 \times \mathrm{g}, 30 \mathrm{~min})$. The core-shell UCNPs were stored in hexane $(10 \mathrm{~mL})$.

\section{Synthesis of UCNPs@SiO}

Twenty milliliter of water with $66 \mathrm{mg}$ of cetyltrimethyl ammonium bromide (CTAB) was mixed in the $60^{\circ} \mathrm{C}$ water bath for $10 \mathrm{~min}$. UCNPs kept in hexane $(2 \mathrm{~mL})$ were added into the solution, and stirred at room temperature for $48 \mathrm{~h}$. The solution became clear and was added to $20 \mathrm{~mL}$ of water. A mixed solution of $0.15 \mathrm{~mL}$ $\mathrm{NaOH}\left(2 \mathrm{~mol} \mathrm{~L}^{-1}\right), 3 \mathrm{~mL}$ of ethanol and $20 \mathrm{~mL}$ water was prepared in a round bottom flask. Then the UCNPs solution was added into the flask in water bath of $70^{\circ} \mathrm{C}$. After the temperature became stable, $0.15 \mathrm{~mL}$ tetraethyl orthosilicate (TEOS) was added into the mixed solution with magnetic stirring for $1.5 \mathrm{~h}$. And then $0.05 \mathrm{~mL} 3$ aminopropyl-triethoxysilane (APTES) was added into the solution with magnetic stirring for $30 \mathrm{~min}$. After the reaction, the product was precipitated by addition of ethanol, separated by centrifugation at 12,000 $\mathrm{rmin}^{-1}$ for three times. The precipitate was dispersed in $10 \mathrm{~mL}$ ethanol and added into $10 \mathrm{~mL}$ ethanol containing $0.3 \mathrm{~g}$ $\mathrm{NH}_{4} \mathrm{NO}_{3}$. The mixture was rapidly heated to $60^{\circ} \mathrm{C}$ and kept at this temperature for $2 \mathrm{~h}$ under vigorous magnetic stirring. After the reaction was completed, the same ethanol was centrifuged and washed for three times at $12,000 \mathrm{r} \mathrm{min}^{-1}$ to obtain UCNPs coated with mesoporous silicon(UCNPs@SiO 2 ).

\section{Synthesis of UCNPs@SiO $@$ @GOx}

1-Ethyl-3-(3-dimethylaminopropyl)carbodimide (EDC, $19.2 \mathrm{mg}$ ), $16 \mathrm{mg}$ of $\mathrm{N}$-hydroxysuccinimide (NHS) and $5 \mathrm{mg}$ of GOx were dissolved into $2 \mathrm{~mL}$ of phosphate buffer saline (PBS, pH 6.0) and stirred for $30 \mathrm{~min}$ at room temperature. Then $2 \mathrm{~mL}$ of UCNPs@SiO $\mathrm{U}_{2}$ aqueous solution $\left(2.5 \mathrm{mg} \mathrm{mL}^{-1}\right)$ was added into the above solution. After reacting for $8 \mathrm{~h}$ under stirring, the UCNPs@ $\mathrm{SiO}_{2} @ G O x$ was separated by centrifugation and washed for three times at $12,000 \mathrm{r} \mathrm{min}^{-1}$.

\section{Characterizations}

The morphology and structure of the as-synthesized nanoparticles were characterized by transmission electron microscopy (TEM, JEM-1230, JEOL). The fourier-transform infrared spectroscopy (FT-IR) spectra were measured on a FT-IR spectrometer (Spectrum Two ${ }^{\mathrm{TM}}$, PerkinElmer). Zeta potential was measured by a Zetasizer Nano ZS90 (Malvern Instruments, UK). The absorbance spectrum assay was tested by a UV-vis spectrophotometer (Agilent Cary60). Electron spin resonance (ESR) spectra were determined by a Bruker EMX Plus spectrometer. The emission spectra of the nanoparticles were recorded by excitation with a $980 \mathrm{~nm}$ laser. The in vitro $\mathrm{H}_{2} \mathrm{O}_{2}$ concentrations were detected with a $\mathrm{H}_{2} \mathrm{O}_{2}$ Assay Kit (Beyotime Institute of Biotechnology, China) via a UVvis spectrophotometer.

\section{RESULTS AND DISCUSSION}

The silica-coated $\mathrm{NaYF}_{4}$ nanoparticles were synthesized by a two-step process according to the published protocol $[36,37]$. First, $\mathrm{NaYF}_{4}: \mathrm{Yb}^{3+}, \mathrm{Tm}^{3+}$ UCNPs were synthesized by a high-temperature thermal decomposition method. The UCNPs were then coated with an amino-modified mesoporous silica layer to get the UCNPs@SiO ${ }_{2}$. Then the GOx was covalently conjugated to UCNPs@SiO ${ }_{2}$ via the formation of amide bonds between the carboxylic groups of GOx and amino groups on the silica layer to get UCNPs@SiO ${ }_{2} @ G O x$ with the help of EDC. The morphology of the UCNPs was characterized by TEM as shown in Fig. 1a. It showed that the UCNPs were monodispersed and the UCNPs@SiO $\mathrm{SiGO}_{2}$ had an average diameter of around $75 \mathrm{~nm}$. As shown in Fig. 1b, the ab-

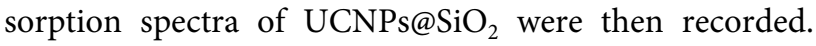
The free UNCPs@SiO ${ }_{2}$ showed no characteristic absorption peak while the UCNPs@SiO $\mathrm{S}_{2} @ \mathrm{GOx}$ showed the characteristic absorption peak of GOx at $280 \mathrm{~nm}$, suggesting the successful conjugation of GOx on the surface of UCNPs@SiO 2 . As shown in Fig. S1, the zeta potential of UCNPs changed from negative to positive after coating with amino-modified silica layer, due to the positively charged amino groups on the surface. After conjugation with GOx, the UCNPs@SiO $\mathrm{S}_{2} @ \mathrm{GOx}$ showed a negative surface charge, which suggested the successful conjugation between the carboxylic groups of GOx and amino groups on the silica layer. Fig. S2 shows that the FT-IR curve of UCNPs@SiO $@ G O x$ has the characteristic peaks of $\mathrm{C}=\mathrm{O}\left(\tilde{v}=1650 \mathrm{~cm}^{-1}\right)$ and $\mathrm{N}-\mathrm{H}\left(\tilde{v}=3350 \mathrm{~cm}^{-1}\right)$ bond of GOx, further suggesting a covalent linkage between GOx and UCNPs@SiO 2 . Further, the conjugation capacity of GOx on UCNPs@SiO $2 @ G O x$ was evaluated, showing the 
a
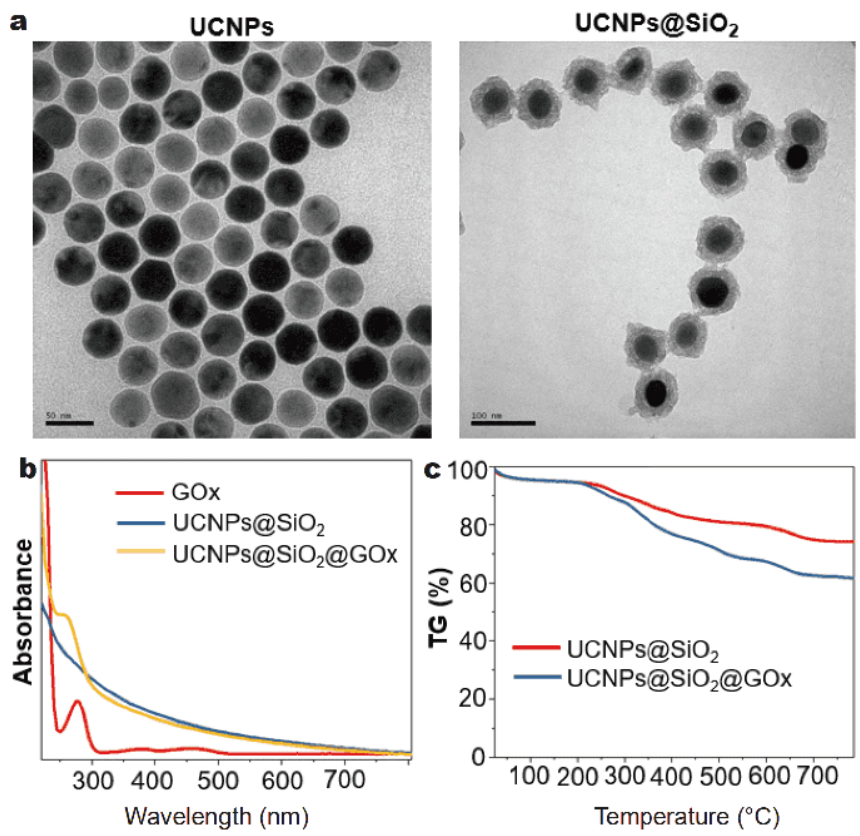

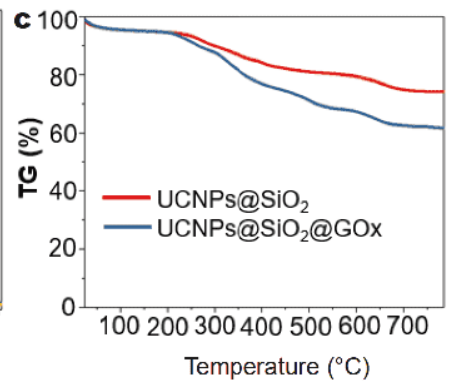

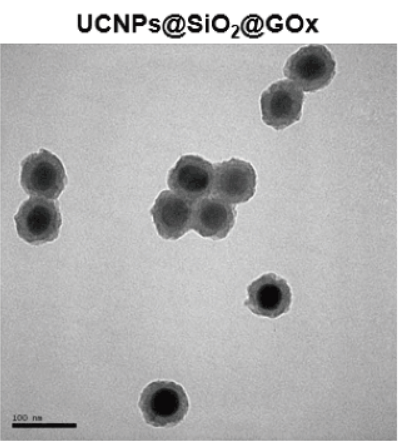

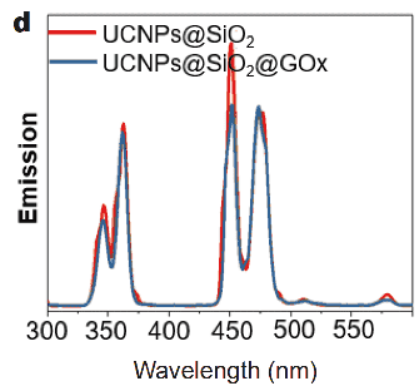

Figure 1 (a) TEM images of the nanoparticles. Scale bar: $50 \mathrm{~nm}, 100 \mathrm{~nm}, 100 \mathrm{~nm}$ (from left to right). (b) UV-vis spectra of UCNPs, UCNPs@SiO 2

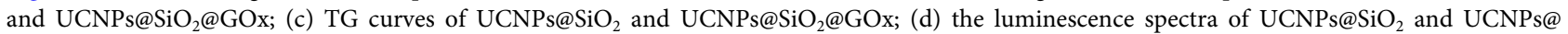
$\mathrm{SiO}_{2} @ \mathrm{GOx}$ under excitation at $980 \mathrm{~nm}$.

saturated GOx loading ratio of $12.3 \mathrm{wt} \%$ via thermogravimetric analysis (TGA) (Fig. 1c). Upon $980 \mathrm{~nm}$ NIR light irradiation, UCNPs@SiO $\mathrm{O}_{2} @ \mathrm{GOx}$ emitted similar emissions in UV and visible regions compared to that of free UCNPs (Fig. 1d), which suggested that the modification with GOx did not affect the upconversion ability of UCNPs.

Afterwards, the $\mathrm{H}_{2} \mathrm{O}_{2}$-generating activity of UCNPs@ $\mathrm{SiO}_{2} @ \mathrm{GOx}$ was then investigated. After the addition of UCNPs@SiO $\mathrm{S}_{2} @ \mathrm{GOx}$ in the glucose solution, the $\mathrm{H}_{2} \mathrm{O}_{2}$ were immediately generated through the GOx-catalyzed glucose oxidation reaction. The concentrations of $\mathrm{H}_{2} \mathrm{O}_{2}$ were correlated to the concentrations of glucose. Furthermore, UCNPs@SiO $\mathrm{SGOx}_{2}$ had about 92\% of the $\mathrm{H}_{2} \mathrm{O}_{2}$-generating activity of native GOx (Fig. 2a), indicating that the activity of GOx was well retained after conjugation. In contrast, the UCNPs@SiO ${ }_{2}$ showed no $\mathrm{H}_{2} \mathrm{O}_{2}$-generating activity. $\mathrm{H}_{2} \mathrm{O}_{2}$ could undergo homolytic cleavage, forming two hydroxyl radicals under invisible ultraviolet light irradiation. Previously, it was reported that the generated $\mathrm{H}_{2} \mathrm{O}_{2}$ by photolysis under invisible ultraviolet light irradiation was used for antibacterial and tumor therapy [24,34,35]. Here, we also discussed the effects of $\mathrm{H}_{2} \mathrm{O}_{2}$ under light irradiation on the generation of $\cdot \mathrm{OH}$ in solution using 3,3',5,5'-tetramethylbenzidine (TMB) as the indicator. TMB can be oxidized to a blue product with a characteristic absorption peak at $652 \mathrm{~nm}$ by $\cdot \mathrm{OH}$ [38]. As shown in Fig. S3, the TMB solution showed increased absorption at $652 \mathrm{~nm}$ from oxidized TMB upon the light irradiation for $30 \mathrm{~min}$ at $450 \mathrm{~nm}$ with different power densities, suggesting the generation of $\cdot \mathrm{OH}$. The blue light irradiation could be replaced by UCNPs, which emit ultraviolet/blue photon under $980 \mathrm{~nm}$ irradiation. As shown in Fig. S4, in the presence of UCNPs, the solution showed increased absorption at $652 \mathrm{~nm}$ from oxidized TMB upon the light irradiation at $980 \mathrm{~nm}$ in a power-dependent manner. Then, the UCNPs@SiO $\mathrm{S}_{2} @ \mathrm{GOx}$ complex was demonstrated to catalyze glucose to produce $\mathrm{H}_{2} \mathrm{O}_{2}$ and emit invisible ultraviolet irradiation under excitation at $980 \mathrm{~nm}$. Therefore, we chose a $980 \mathrm{~nm}$ light source to produce $\cdot \mathrm{OH}$ with the combination of UCNPs@SiO $\mathrm{S}_{2} @ \mathrm{GOx}$ and glucose. We used UV-vis-NIR absorption and ESR spectroscopy assay to detect the $\cdot \mathrm{OH}$ generated by the photolysis of $\mathrm{H}_{2} \mathrm{O}_{2}$. As shown in Fig. 2b, the TMB solution containing UCNPs@SiO $@$ @GOx and glucose showed no absorption at $652 \mathrm{~nm}$ before light irradiation at $980 \mathrm{~nm}$. Upon irradiation at $980 \mathrm{~nm}$, the absorbance at $652 \mathrm{~nm}$ gradually increased in a time-dependent manner (Fig. 2c). This phenomenon might be attributed to the oxidation of TMB by.OH. In this system, UCNPs@SiO ${ }_{2} @ G O x$ catalyzed glucose to $\mathrm{H}_{2} \mathrm{O}_{2}$, and then $\mathrm{H}_{2} \mathrm{O}_{2}$ was photolyzed to 

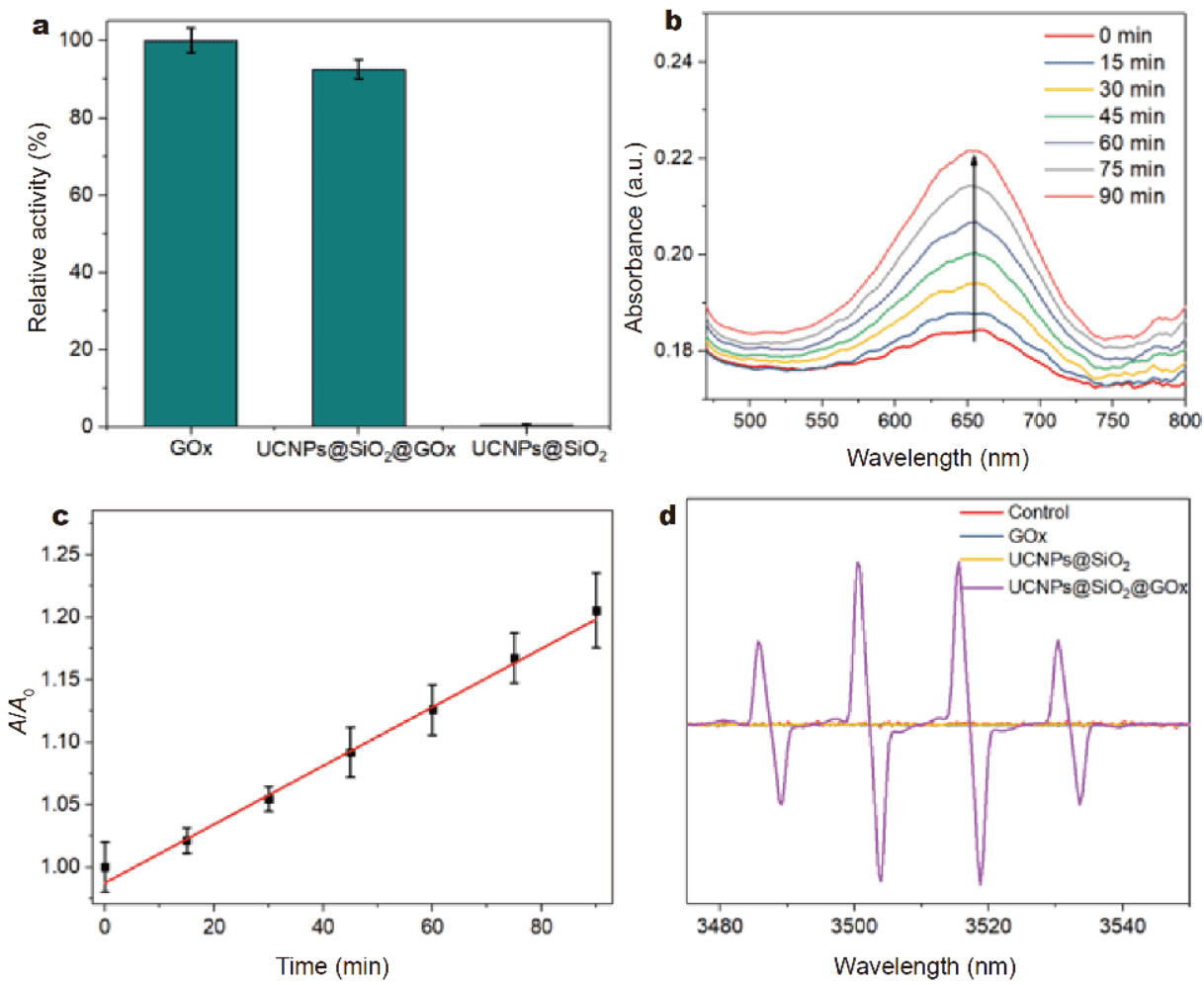

Figure 2 (a) Relative activity of GOx, UCNPs@SiO ${ }_{2}$, and UCNPs@SiO $@$ @GOx; (b) absorption spectra of TMB in the presence of glucose and UCNPs@SiO ${ }_{2} @ G O x$ with different times of light irradiation at $980 \mathrm{~nm}\left(1 \mathrm{~W} \mathrm{~cm}{ }^{-2}\right)$ ([TMB] $=10 \mathrm{mmol} \mathrm{L}^{-1}$, [glucose] $=20 \mathrm{mmol} \mathrm{L}^{-1}$, [UCNPs@ $\left.\mathrm{SiO}_{2} @ \mathrm{GOx}\right]=2 \mathrm{mg} \mathrm{mL}^{-1}$ ); (c) absorption intensity of the oxidized TMB at $652 \mathrm{~nm}$ as a function of irradiation time for the UCNPs@SiO $@ G O x . A$ and $A_{0}$ were the absorption intensities of the TMB system solution without light irradiation at $980 \mathrm{~nm}$. The error bars represent the standard deviations of three separate measurements. (d) ESR spectra of different groups treated with glucose and 5,5-dimethyl-1-pyrroline N-oxide (DMPO) under light irradiation at $980 \mathrm{~nm}$.

.OH that oxidized colorless TMB to chromogenic TMB. In addition, the characteristic .OH-induced 1:2:2:1 quadruple peaks were observed in the ESR spectra in the glucose solution after treatment with UCNPs@SiO ${ }_{2} @ G O x$ under $980 \mathrm{~nm}$ light irradiation (Fig. 2d), further confirming the generation of $\mathrm{OH}$. In contrast, when the glucose solution was treated by the PBS (control), GOx or UCNPs@SiO ${ }_{2}$, there was no ·OH characteristic ESR peak, which further suggested that GOx first catalyzed the oxidation of glucose with the production of $\mathrm{H}_{2} \mathrm{O}_{2}$ and the generated $\mathrm{H}_{2} \mathrm{O}_{2}$ was photolyzed by the invisible ultraviolet emission of the UCNPs under NIR excitation at $980 \mathrm{~nm}$. This cascade system exhibited spatiotemporally controlled cancer therapy.

After that, the effects of UCNPs@SiO $\mathrm{S}_{2} @ \mathrm{GOx}$ on 4T1 cancer cells were studied. The intracellular $\mathrm{H}_{2} \mathrm{O}_{2}$ production ability was tested via a reactive oxygen probe (DCFH-DA) [39]. As shown in Fig. S5, the 4T1 cells showed no green DCF fluorescence in the control and UCNPs@SiO ${ }_{2}$ groups. But a bright DCF fluorescence was found in $4 \mathrm{~T} 1$ cells after treatment with GOx and UCNPs@SiO ${ }_{2} @ G O x$, which was ascribed to the generation of $\mathrm{H}_{2} \mathrm{O}_{2}$ by GOx. Next, the cytotoxicity of UCNPs@SiO ${ }_{2} @ G O x$ at different concentrations was investigated. For comparison purpose, the cytotoxicities of UCNPs@SiO $2, G O x$, and PBS were also measured. As depicted in Fig. 3a, UCNPs@SiO ${ }_{2}$ at low concentrations $\left(\leq 40 \mu \mathrm{g} \mathrm{mL}^{-1}\right)$ had no obvious cytotoxicity. However, after conjugation with $\mathrm{GOx}$, the cytotoxicity of UCNPs@SiO ${ }_{2} @ G O x$ was greatly increased and caused about $65 \%$ of cell death at the concentration of $40 \mu \mathrm{g} \mathrm{mL}^{-1}$ in the dark condition. This is probably due to the high level of $\mathrm{H}_{2} \mathrm{O}_{2}$ and glucose exhaustion caused by GOx. Subsequently, the synergistic effect of PDT on starving therapy on $4 \mathrm{~T} 1$ cancer cells was investigated. As shown in Fig. 3b, the 4T1 cell viability in the UCNPs@ $\mathrm{SiO}_{2}$ after exposure to light illumination for $20 \mathrm{~min}$ $\left(980 \mathrm{~nm}, 0.6 \mathrm{~W} \mathrm{~cm}^{-2}\right)$ had a weak decrease compared with that in dark condition. However, the cell viability in the group of UCNPs@SiO ${ }_{2} @ G O x$ significantly decreased 

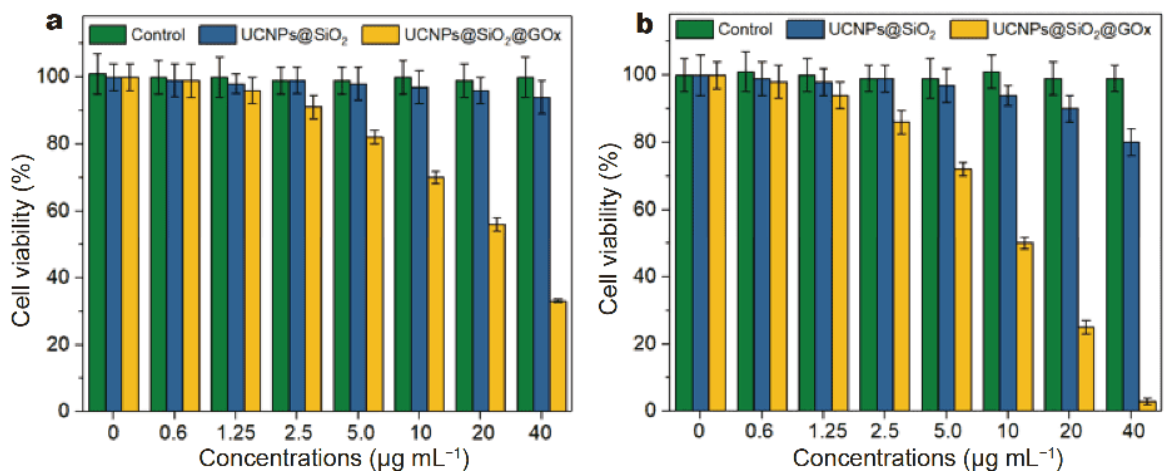

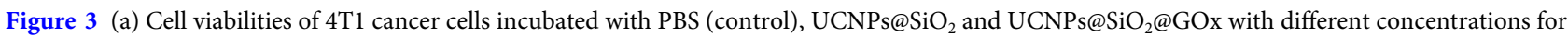

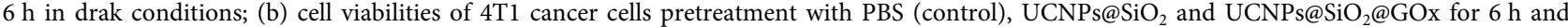
treated with light irradiation at $980 \mathrm{~nm}\left(0.6 \mathrm{~W} \mathrm{~cm}{ }^{-2}, 20 \mathrm{~min}\right)$. The error bars represent the standard deviations of three separate measurements.

after light irradiation under the same condition compared with that in dark condition, indicating the efficient synergistic effects of PDT on starving therapy.

Moreover, the effective synergistic therapeutic performance was also intuitively confirmed by the live/dead (Calcein-AM/propidium iodide (PI)) cell co-staining assay (Fig. 4). The live/dead staining results exhibited obvious cell death after treatment with UCNPs@SiO $\mathrm{U}_{2} @ \mathrm{GOx}$ and light irradiation compared with the control group (PBS) or in the absence of light irradiation. It is worth mentioning that the free GOx at low concentrations $\left(\leq 30 \mathrm{ng} \mathrm{mL}^{-1}\right)$ had obvious cytotoxicity to $4 \mathrm{~T} 1$ cancer cells (Fig. S6). But it did not produce any phototoxicity on the cells after irradiation at $980 \mathrm{~nm}$ (Fig. S6), which further suggested that the synergistic effects of combination PDT and starving therapy only existed in the UCNPs@ $\mathrm{SiO}_{2} @ \mathrm{GOx}$ system. In addition, some reports have proven that the free GOx failed to exhibit effective antitumor activity in vivo [40].

Therefore, it is needed to develop the multifunctional nanoparticles to optimize the GOx-involved synergistic therapy and guarantee an effetive therapy efficacy in animal study.

The in vivo anticancer effects of UCNPs@SiO ${ }_{2} @ G O x$ under light irradiation at $980 \mathrm{~nm}$ were evaluated on 4T1 cancer-bearing mouse model (see the detail experimental procedures in the Supplementary information). All the animal experiments were conformed to the guidelines set by the Animal Ethical and Welfare Committee of Shenzhen University (AEWC-SZU). As shown in Fig. 5a, rapidly progressive growth of tumors was observed after treatment with free GOx and light irradiation compared with the control group treatment with PBS under light irradiation, which suggested that the GOx was negative in inhibiting tumor growth compared with PBS and the light

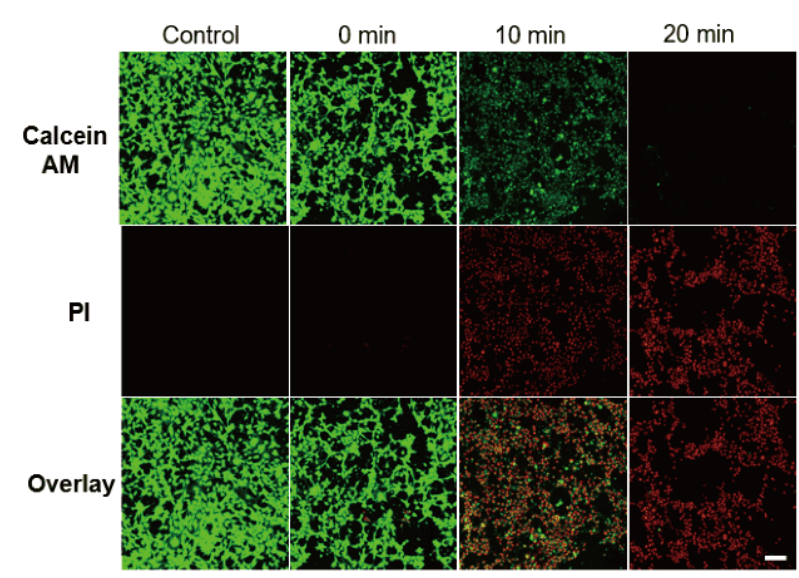

Figure 4 Fluorescent images of $4 \mathrm{~T} 1$ cancer cells with Calcein-AM/PI staining after different treatment. Cells were pre-treatment with PBS (control) or UCNPs@SiO $@ G O x\left(0.05 \mathrm{mg} \mathrm{mL}^{-1}\right)$ for $6 \mathrm{~h}$, and then treated with light irradiation at $980 \mathrm{~nm}\left(0.6 \mathrm{~W} \mathrm{~cm}^{-2}, 20 \mathrm{~min}\right)$. CalceinAM: $\lambda_{\mathrm{ex}}=488 \mathrm{~nm}, \lambda_{\mathrm{em}}=515 \mathrm{~nm}$; PI: $\lambda_{\mathrm{em}}=600-630 \mathrm{~nm}, \lambda_{\mathrm{ex}}=536 \mathrm{~nm}$. Scale bar: $200 \mu \mathrm{mol} \mathrm{L}$.

irradiation at $980 \mathrm{~nm}$ could not directly provide synergistic therapy effect without the UCNPs. UCNPs@ $\mathrm{SiO}_{2}$ were found to have a weak inhibition of tumor growth under light irradiation. Moreover, UCNPs@ $\mathrm{SiO}_{2} @ \mathrm{GOx}$ exhibited a certain tumor growth inhibition in the absence of light, which was ascribed to its starvation therapeutic effects. Furthermore, the mice after treatment with UCNPs@SiO $@ @ G O x$ and light irradiation showed the most effective tumor inhibition compared with all other control groups. The results indicated that the UCNPs@SiO ${ }_{2} @ G O x-m e d i a t e d$ starving- and photodynamic therapy had efficiently synergistic therapy efficacy, much better than mono treatment.

To visually determine the therapeutic outcome of different treatments, the representative photos of tumor- 

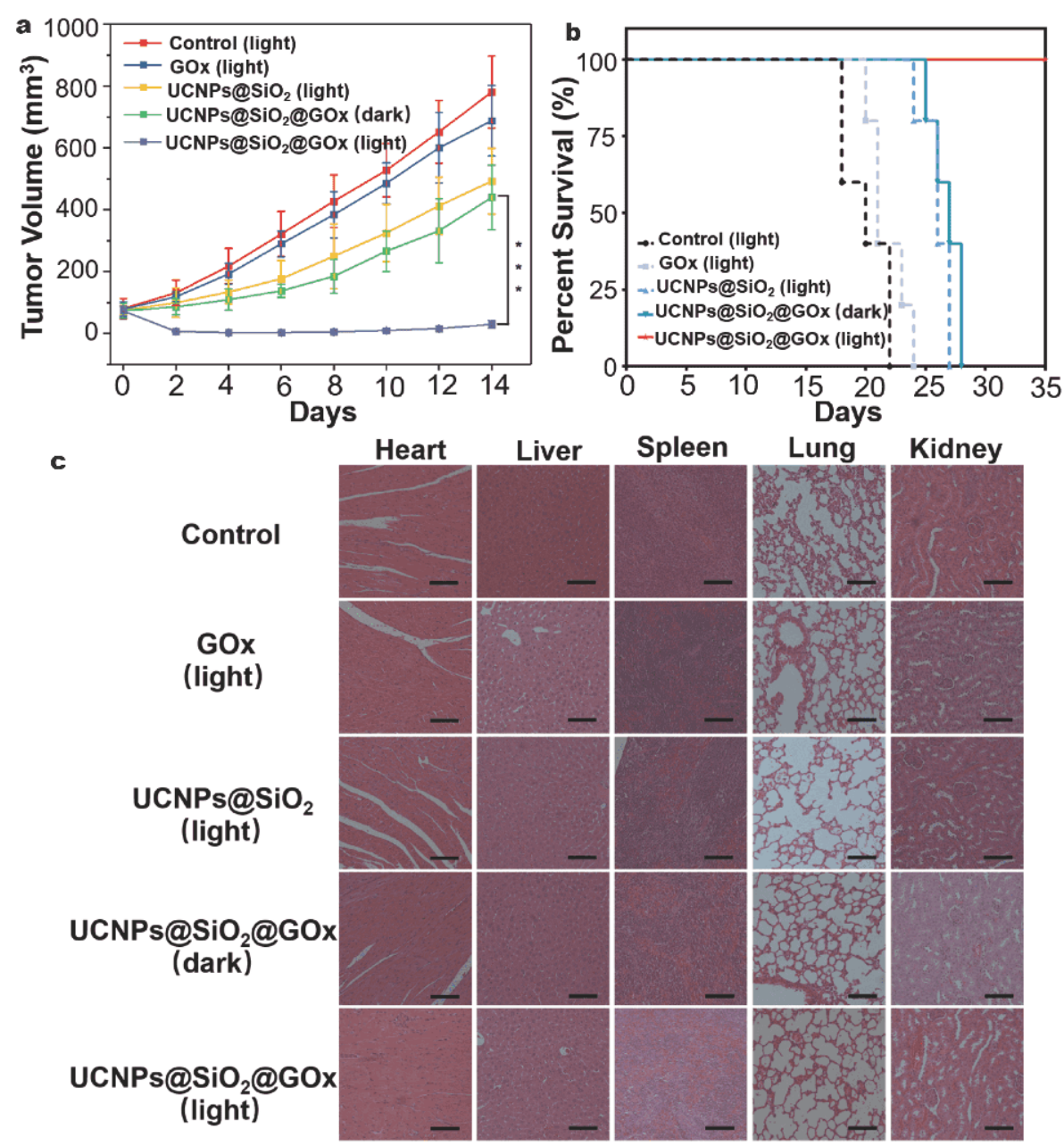

Figure 5 (a) Tumor growth curves after different treatments with PBS (control), GOx, UCNPs@SiO $\mathrm{O}_{2}$ and UCNPs@SiO $@$ @Ox in dark or light conditions (dark indicates a dark condition; light indicates light irradiation at $980 \mathrm{~nm}$ of $0.6 \mathrm{~W} \mathrm{~cm}^{-2}$ for $30 \mathrm{~min}$. Data are shown as mean \pm standard deviation $\left(n=5 ;{ }^{* * *} P<0.001\right)$. (b) Survival curves of the mice after the treatments obtained from (a). (c) Representative H\&E staining images of major organs (heart, liver, spleen, lung and kidney) after different treatments. Scale bar: $100 \mu \mathrm{m}$.

bearing mice were photographed after the therapy process (Fig. S7). These photos directly demonstrated the most efficient tumor inhibition after treatment with UCNPs@SiO ${ }_{2} @ G O x$ and light irradiation. As a result, the mice after treatment with UCNPs@SiO $\mathrm{S}_{2} @ \mathrm{GOx}$ and light irradiation exhibited a much better animal survival in 35 days than the other groups (Fig. 5b), which further confirmed the enhanced in vivo therapeutic efficacy of the synergistic starving- and photodynamic therapy. In addition, no significant body weight change was observed in all groups during the 15 days of the treatment process (Fig. S8). No obvious hemolysis was induced by UCNPs@SiO $@$ @GOx at a high concentration of $100 \mu \mathrm{g} \mathrm{mL}^{-1}$ (Fig. S9), indicating that the injection of UCNPs@SiO ${ }_{2} @ G O x$ had no significant toxicity during the treatment. The glutamic-pyruvic transaminase (ALT), urea nitrogen (BUN), glutamic oxalacetic transaminase (AST) and creatinine (CREA) levels from healthy nude mice at 15 days post-injection of UCNPs@SiO $\mathrm{U}_{2} @ \mathrm{GOx}$ were found to be kept stable levels compared with the control group. No significant change in major organ histomorphology was observed after different treatments (Fig. 5c and Fig. S10). These results indicated that the UCNPs@SiO $@$ @GOx had good biocompatibility and did not cause severe toxicity in vivo during the therapy.

\section{CONCLUSIONS}

In summary, a type of NIR-responsive GOx-conjugated UCNPs, UCNPs@SiO $\mathrm{S}_{2} @ \mathrm{GOx}$, was constructed to improve the anticancer efficiency through cascade glucose 
oxidation and hydrogen peroxide photolysis. The UCNPs@SiO ${ }_{2} @ G O x$ agents absorb the 980 nm light and convert the low-energy light into high-energy invisible ultraviolet radiation for PDT. After administration, the UCNPs@SiO ${ }_{2} @ G O x$ efficiently catalyzed the oxidation of glucose with production of $\mathrm{H}_{2} \mathrm{O}_{2}$, producing the anticancer activities of starving therapy and $\mathrm{H}_{2} \mathrm{O}_{2}$ therapy. Meanwhile, the $\mathrm{H}_{2} \mathrm{O}_{2}$ could be photolyzed to generate two·OH radicals by UCNPs@SiO $@$ @Ox with the irradiation at $980 \mathrm{~nm}$, which greatly improved the anticancer ability and inhibited the tumor growth with less side effects. This study would provide a new insight into the design and construction of multifunctional nanoparticles for cancer synergistic therapy.

\section{Received 24 October 2019; accepted 2 December 2019;} published online 8 January 2020

1 Song $\mathrm{X}, \mathrm{Xu}$ J, Liang $\mathrm{C}$, et al. Self-supplied tumor oxygenation through separated liposomal delivery of $\mathrm{H}_{2} \mathrm{O}_{2}$ and catalase for enhanced radio-immunotherapy of cancer. Nano Lett, 2018, 18: 6360-6368

2 Zhang MK, Li CX, Wang SB, et al. Tumor starvation induced spatiotemporal control over chemotherapy for synergistic therapy. Small, 2018, 14: 1803602

3 Feng W, Han X, Wang R, et al. Nanocatalysts-augmented and photothermal-enhanced tumor-specific sequential nanocatalytic therapy in both NIR-I and NIR-II biowindows. Adv Mater, 2018, 55: 1805919

4 Song R, Zhang M, Liu Y, et al. A multifunctional nanotheranostic for the intelligent MRI diagnosis and synergistic treatment of hypoxic tumor. Biomaterials, 2018, 175: 123-133

5 Chen W, Liu J, Wang Y, et al. A $\mathrm{C}_{5} \mathrm{~N}_{2}$ nanoparticle based direct nucleus delivery platform for synergistic cancer therapy. Angew Chem Int Ed, 2019, 58: 6290-6294

6 Fan W, Yung B, Huang P, et al. Nanotechnology for multimodal synergistic cancer therapy. Chem Rev, 2017, 117: 13566-13638

7 Yang B, Chen Y, Shi J. Reactive oxygen species (ROS)-based nanomedicine. Chem Rev, 2019, 119: 4881-4985

8 Jiang Y, Li J, Zeng Z, et al. Organic photodynamic nanoinhibitor for synergistic cancer therapy. Angew Chem, 2019, 131: 8245-8249

9 Zhang X, Du J, Guo Z, et al. Efficient near infrared light triggered nitric oxide release nanocomposites for sensitizing mild photothermal therapy. Adv Sci, 2019, 6: 1801122

10 Zeng L, Gupta P, Chen Y, et al. The development of anticancer ruthenium(ii) complexes: from single molecule compounds to nanomaterials. Chem Soc Rev, 2017, 46: 5771-5804

11 Hao H, Sun M, Li P, et al. In situ growth of a cationic polymer from the $\mathrm{N}$-terminus of glucose oxidase to regulate $\mathrm{H}_{2} \mathrm{O}_{2}$ generation for cancer starvation and $\mathrm{H}_{2} \mathrm{O}_{2}$ therapy. ACS Appl Mater Interfaces, 2019, 11: 9756-9762

12 Zhang L, Wang Z, Zhang Y, et al. Erythrocyte membrane cloaked metal-organic framework nanoparticle as biomimetic nanoreactor for starvation-activated colon cancer therapy. ACS Nano, 2018, 12: 10201-10211

$13 \mathrm{He} \mathrm{T}$, Xu H, Zhang Y, et al. Glucose oxidase-instructed traceable self-oxygenation/hyperthermia dually enhanced cancer starvation therapy. Theranostics, 2019, doi: 10.7150/thno.40439

14 Fu LH, Qi C, Hu YR, et al. Glucose oxidase-instructed multimodal synergistic cancer therapy. Adv Mater, 2019, 31: 1808325

15 Huo M, Wang L, Chen Y, et al. Tumor-selective catalytic nanomedicine by nanocatalyst delivery. Nat Commun, 2017, 8: 357

16 Zhang R, Feng L, Dong Z, et al. Glucose \& oxygen exhausting liposomes for combined cancer starvation and hypoxia-activated therapy. Biomaterials, 2018, 162: 123-131

17 Fu LH, Qi C, Lin J, et al. Catalytic chemistry of glucose oxidase in cancer diagnosis and treatment. Chem Soc Rev, 2018, 47: 64546472

18 Fan W, Lu N, Huang P, et al. Glucose-responsive sequential generation of hydrogen peroxide and nitric oxide for synergistic cancer starving-like/gas therapy. Angew Chem Int Ed, 2017, 56: 1229-1233

19 Zhang Y, Yang Y, Jiang S, et al. Degradable silver-based nanoplatform for synergistic cancer starving-like/metal ion therapy. Mater Horiz, 2019, 6: 169-175

20 Zhang L, Wan SS, Li CX, et al. An adenosine triphosphate-responsive autocatalytic fenton nanoparticle for tumor ablation with self-supplied $\mathrm{H}_{2} \mathrm{O}_{2}$ and acceleration of $\mathrm{Fe}(\mathrm{III}) / \mathrm{Fe}(\mathrm{II})$ conversion. Nano Lett, 2018, 18: 7609-7618

21 Yang Y, Lu Y, Abbaraju PL, et al. Stepwise degradable nanocarriers enabled cascade delivery for synergistic cancer therapy. Adv Funct Mater, 2018, 28: 1800706

22 Li J, Li Y, Wang Y, et al. Polymer prodrug-based nanoreactors activated by tumor acidity for orchestrated oxidation/chemotherapy. Nano Lett, 2017, 17: 6983-6990

23 Yu Z, Zhou P, Pan W, et al. A biomimetic nanoreactor for synergistic chemiexcited photodynamic therapy and starvation therapy against tumor metastasis. Nat Commun, 2018, 9: 5044

24 Chang K, Liu Z, Fang X, et al. Enhanced phototherapy by nanoparticle-enzyme via generation and photolysis of hydrogen peroxide. Nano Lett, 2017, 17: 4323-4329

25 Li SY, Cheng H, Xie BR, et al. Cancer cell membrane camouflaged cascade bioreactor for cancer targeted starvation and photodynamic therapy. ACS Nano, 2017, 11: 7006-7018

26 Lü B, Chen Y, Li P, et al. Stable radical anions generated from a porous perylenediimide metal-organic framework for boosting near-infrared photothermal conversion. Nat Commun, 2019, 10: 767

27 Ma Y, Bao J, Zhang Y, et al. Mammalian near-infrared image vision through injectable and self-powered retinal nanoantennae. Cell, 2019, 177: 243-255.e15

28 Zhang Z, Jayakumar MKG, Zheng X, et al. Upconversion superballs for programmable photoactivation of therapeutics. Nat Commun, 2019, 10: 4586

29 All AH, Zeng X, Teh DBL, et al. Expanding the toolbox of upconversion nanoparticles for in vivo optogenetics and neuromodulation. Adv Mater, 2019, 31: 1803474

30 Dong $\mathrm{S}, \mathrm{Xu}$ J, Jia $\mathrm{T}$, et al. Upconversion-mediated $\mathrm{ZnFe}_{2} \mathrm{O}_{4}$ nanoplatform for NIR-enhanced chemodynamic and photodynamic therapy. Chem Sci, 2019, 10: 4259-4271

31 Zhong $\mathrm{Y}, \mathrm{Ma} \mathrm{Z}$, Wang $\mathrm{F}$, et al. In vivo molecular imaging for immunotherapy using ultra-bright near-infrared-IIb rare-earth nanoparticles. Nat Biotechnol, 2019, 37: 1322-1331

32 Zhang M, Zheng W, Liu Y, et al. A new class of blue-LED-excitable NIR-II luminescent nanoprobes based on lanthanide-doped CaS nanoparticles. Angew Chem Int Ed, 2019, 58: 9556-9560

33 Gao Y, Li R, Zheng W, et al. Broadband NIR photostimulated 
luminescence nanoprobes based on $\mathrm{CaS}: \mathrm{Eu}^{2+}, \mathrm{Sm}^{3+}$ nanocrystals. Chem Sci, 2019, 10: 5452-5460

34 Lucky SS, Muhammad Idris N, Li Z, et al. Titania coated upconversion nanoparticles for near-infrared light triggered photodynamic therapy. ACS Nano, 2015, 9: 191-205

$35 \mathrm{Gu} \mathrm{Y,} \mathrm{Guo} \mathrm{Z,} \mathrm{Yuan} \mathrm{W,} \mathrm{et} \mathrm{al.} \mathrm{High-sensitivity} \mathrm{imaging} \mathrm{of} \mathrm{time-}$ domain near-infrared light transducer. Nat Photonics, 2019, 13: 525-531

36 Qian HS, Guo HC, Ho PCL, et al. Mesoporous-silica-coated upconversion fluorescent nanoparticles for photodynamic therapy. Small, 2009, 5: 2285-2290

37 Liang $\mathrm{T}$, Li Z, Wang $\mathrm{P}$, et al. Breaking through the signal-tobackground limit of upconversion nanoprobes using a targetmodulated sensitizing switch. J Am Chem Soc, 2018, 140: 1469614703

38 Li X, Sun L, Yang X, et al. Enhancing the colorimetric detection of $\mathrm{H}_{2} \mathrm{O}_{2}$ and ascorbic acid on polypyrrole coated fluconazole-functionalized POMOFs. Analyst, 2019, 144: 3347-3356

39 Li M, Long S, Kang Y, et al. De novo design of phototheranostic sensitizers based on structure-inherent targeting for enhanced cancer ablation. J Am Chem Soc, 2018, 140: 15820-15826

40 Zhao W, Hu J, Gao W. Glucose oxidase-polymer nanogels for synergistic cancer-starving and oxidation therapy. ACS Appl Mater Interfaces, 2017, 9: 23528-23535

Acknowledgements This work was financially supported by the National Natural Science Foundation of China (21807073, 31771036 and 51703132), the Basic Research Program of Shenzhen (JCYJ20170818144745087, JCYJ20180507182413022 and JCYJ20170412111100742), Guangdong Province Natural Science Foundation of Major Basic Research and Cultivation Project (2018B030308003), Fok Ying-Tong Education Foundation for Young Teachers in the Higher Education Institutions of China (161032), and China Postdoctoral Science Foundation (2018M630987 and 2019T120752). We thank Instrumental Analysis Center of Shenzhen University (Lihu Campus).

Author contributions Zeng L, Huang K and Huang P conceived the idea, proposed the strategy, performed the experiments and wrote the manuscript. Wan Y, Zhang J, and Jiang C performed the cell and animal experiments. Yao $\mathrm{X}$ and Lin $\mathrm{J}$ helped writing and modifying the manuscript. Huang P supervised the study, designed the project, evaluated the data and wrote the manuscript.

Conflict of interest The authors declare that they have no conflict of interest.

Supplementary information online version of the paper.

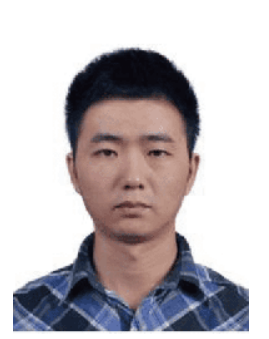

Leli Zeng received his $\mathrm{PhD}$ degree from Sun YatSen University in 2017. During 2016-2017, he conducted a one-year study at St. John's University as a visiting scholar. In 2017-2019, he came to Shenzhen University as a postdoctoral fellow. Now he works in the Seventh Affiliated Hospital, Sun Yat-sen University as a distinguished associate research fellow. His current research interest is focused on organic molecular probe, metal-based anticancer complexes and nanomaterials for molecular detection and cancer therapy.

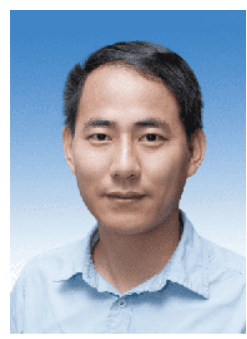

Peng Huang is a distinguished professor, Chief of the Laboratory of Evolutionary Theranostics (LET), and director of the Department of Molecular Imaging, at the School of Biomedical Engineering, Shenzhen University Health Science Center, China. He received his $\mathrm{PhD}$ degree in Biomedical Engineering from Shanghai Jiao Tong University in 2012. He then joined the Laboratory of Molecular Imaging and Nanomedicine (LOMIN) at the National Institutes of Health (NIH) as a postdoctoral fellow. In 2015, he moved to Shenzhen University as a distinguished professor. His research focuses on the design, syntheses, and biomedical applications of multifunctional nanomaterials. Starting from 2008, Dr. Huang has authored over 170 peer-reviewed papers, which have received total citations of $>11,000$ times and given him an H-index of 58 .

\section{程序化饥饿与光动力协同癌症治疗研究}

曾乐立 ${ }^{1,2}$, 黄凯 ${ }^{1}$, 万艺林 ${ }^{1}$, 张景 ${ }^{1}$, 姚锡矿 ${ }^{1}$, 蒋超 ${ }^{1}$, 林静 ${ }^{1}$, 黄鹏 ${ }^{*}$

摘要 协同治疗是指将多种治疗方法联合在一起使用, 从而显著增 强治疗效果. 然而, 如何设计出理想的组合以最大限度地发挥协同 效应仍是肿瘤治疗的一大挑战. 在此, 我们构建了一种由葡萄糖氧 化酶修饰的上转换纳米制剂, 用于程序化的肿瘤饥饿-光动力协同 治疗研究. 葡萄糖氧化酶催化氧化肿瘤内的葡萄糖并产生过氧化 氢, 该过程消耗葡萄糖和氧气, 使得肿瘤细胞缺乏营养物质处于 “饥饿”状态, 导致细胞死亡. 并且在 $980 \mathrm{~nm}$ 的近红外光激发下, 上 转换纳米颗粒激发产生紫外可见光, 将双氧水裂解成毒性更强的 差基自由基, 进一步杀死肿瘤细胞. 体外和体内实验均证实这种饥 饿-光动力协同治疗明显优于任何单一治疗. 本研究为设计程序可 控的饥饿-光动力协同治疗提供了理论支撑. 